Article

\title{
Genome-Wide Identification and Expression Profiling of Monosaccharide Transporter Genes Associated with High Harvest Index Values in Rapeseed (Brassica napus L.)
}

\author{
Liyuan Zhang ${ }^{1,2}$, Chao Zhang ${ }^{1,2}$, Bo Yang ${ }^{1,2}$, Zhongchun Xiao ${ }^{1,2}$, Jinqi Ma 1,2 ${ }^{\mathbb{D}}$, Jingsen Liu ${ }^{1,2}$, \\ Hongju Jian ${ }^{1,2}$, Cunmin Qu ${ }^{1,2}$, Kun Lu $^{3}$ (D) and Jiana Li ${ }^{1,2, *}$ \\ 1 Chongqing Rapeseed Engineering Research Center, College of Agronomy and Biotechnology, Southwest \\ University, Chongqing 400715, China; Liyuanzhang0215@163.com (L.Z.); 18083606406@163.com (C.Z.); \\ sheepneck@hotmail.com (B.Y.); xzc729609100@163.com (Z.X.); jinqima1996@163.com (J.M.); \\ Ljs282355@email.swu.edu.cn (J.L.); hjjian518@swu.edu.cn (H.J.); drqucunmin@swu.edu.cn (C.Q.) \\ 2 Academy of Agricultural Sciences, Southwest University, Chongqing 400715, China \\ 3 State Cultivation Base of Crop Stress Biology for Southern Mountainous Land of Southwest University, \\ Beibei, Chongqing 400715, China; drlukun@swu.edu.cn \\ * Correspondence: ljn1950@swu.edu.cn; Tel.: +86-23-68250642
}

Received: 15 May 2020; Accepted: 12 June 2020; Published: 15 June 2020

\begin{abstract}
Sugars are important throughout a plant's lifecycle. Monosaccharide transporters (MST) are essential sugar transporters that have been identified in many plants, but little is known about the evolution or functions of MST genes in rapeseed (Brassica napus). In this study, we identified 175 MST genes in B. napus, 87 in Brassica oleracea, and 83 in Brassica rapa. These genes were separated into the sugar transport protein (STP), polyol transporter (PLT), vacuolar glucose transporter (VGT), tonoplast monosaccharide transporter (TMT), inositol transporter (INT), plastidic glucose transporter (pGlcT), and ERD6-like subfamilies, respectively. Phylogenetic and syntenic analysis indicated that gene redundancy and gene elimination have commonly occurred in Brassica species during polyploidization. Changes in exon-intron structures during evolution likely resulted in the differences in coding regions, expression patterns, and functions seen among BnMST genes. In total, 31 differentially expressed genes (DEGs) were identified through RNA-seq among materials with high and low harvest index (HI) values, which were divided into two categories based on the qRT-PCR results, expressed more highly in source or sink organs. We finally identified four genes, including BnSTP5, BnSTP13, BnPLT5, and BnERD6-like14, which might be involved in monosaccharide uptake or unloading and further affect the $\mathrm{HI}$ of rapeseed. These findings provide fundamental information about MST genes in Brassica and reveal the importance of BnMST genes to high HI in B. napus.
\end{abstract}

Keywords: monosaccharide transporter; phylogenetic analysis; expression pattern; harvest index; Brassica napus

\section{Introduction}

Photosynthetic products play essential roles in plant growth and development. These products, particularly sugars (including polyols, monosaccharides, and sucrose), are synthesized in photosynthetic organs (source tissues) [1,2] and transported to heterotrophic cells (sink tissues) [3]. The transport and distribution of sugars are important for maintaining the balance between source and sink tissues $[4,5]$. Plants contain two major types of sugar transporters: sucrose transporters and monosaccharide transporters (MSTs) [6]. MSTs are important transmembrane transporters that have been identified in many land plants and that function in carbohydrate flux $[7,8]$. 
The transport and distribution of sugars in plants occur via a complex process. Most plants synthesize starch in source organs following photosynthesis during the daytime [1]. At night, the starch is broken down via a hydrolytic or phosphorolytic pathway [9,10], allowing the products to be easily transported. Sucrose is the major form of photoassimilate that is transported from the source to sink organ via the phloem $[3,11]$. Following the long-distance transport of sucrose through the phloem, sucrose unloading into the sink tissue occurs via two major processes: symplasmic unloading [12-14] and apoplasmic unloading [10]. During symplasmic unloading, sucrose is directly exported into sink tissue. In contrast, both an enzyme (such as the cell wall-bound invertase (CWI)) [15] and a monosaccharide transmembrane transporter (MST) are required for apoplasmic unloading. During this process, the sucrose is broken down into different monosaccharides by invertase [14,16,17], and the monosaccharides are then transported by MSTs $[18,19]$.

The first monosaccharide transporter gene identified, CkHUP1, was cloned via differential screening in Chlorella. This gene encodes a monosaccharide- $\mathrm{H}^{+}$symporter [20]. Based on this finding, MST genes highly homologous to CkHUP1 were cloned in Arabidopsis thaliana, as well as tobacco [21,22]. Increasing numbers of MST genes have been identified in various plants, including 53 MSTs in Arabidopsis [8], 64 in rice [23], and 5 in grapevine [24]. MSTs are important members of the major facilitator superfamily [25,26], and all of them contain 12 transmembrane domains. In Arabidopsis, MSTs can alter cellular sugar partitioning and sugar signaling and further increase the seed yield and biomass [27]. In rice, OsMST4 functions to transport monosaccharide during the seed developmental process [28]. Ngampanya's study provided a new insight into OsMST5, which functions in pollen development [29]. However, to date, no MSTs have been identified in Brassica napus.

Rapeseed (Brassica napus L.; AACC, $2 \mathrm{n}=38$ ) is the most important oilseed crop worldwide. Its seeds can be used to produce oil, its stem and leaves can be used for animal feed, and it can also be used to produce both biofuel and healthcare products [30]. The harvest index (HI), i.e., the ratio of seed yield to aboveground biomass, is one of the most important phenotypic traits of rapeseed. In the past few decades, rapeseed yields have significantly improved, but its HI remains lower than that of other crops [31,32]. Among the three factors affecting the HI-"source", "flow", and "sink" - the lack of sufficient sources and large sinks are not the main factors limiting the $\mathrm{HI}$ in B. napa [33]. Instead, the process of "flow" is the key limiting factor for the seed yield [34,35]. MST genes have crucial effects on carbohydrate flux [7], thereby influencing the biomass and seed yields [28,36-38]. To date, MSTs have been reported in various plant species, including Arabidopsis [8,23], grape [39], rice [38,40], cassava [41], pear [42], and Lupinus polyphyllus [43]. However, a genome-wide identification and expression analysis of MST genes has not previously been performed in B. napus.

In the present study, to explore the evolutionary relationships of MST genes in Brassica species, we performed genome-wide identification of MSTs in B. napus and its two parental species B. oleracea and $B$. rapa. We then performed phylogenetic analysis of these genes among three species, as well as A. thaliana. In total, we identified 175 MST genes in B. napus. By examining RNA sequencing (RNA-seq) data from four HI B. napus materials, we identified 31 differentially expressed genes (DEGs) with significantly different expression levels between seeds and silique pericarps. The expression patterns of these 31 DEGs were confirmed by qRT-PCR in two materials with extremely high and low HI values. We ultimately identified four candidate genes that might promote carbohydrate flux and increase the $\mathrm{HI}$ in B. napus.

\section{Materials and Methods}

\subsection{Identification of MSTs in B. napus, B. rapa and B. oleracea}

The deduced protein sequences of AtMST genes were obtained from the Arabidopsis Information Resource database (https://www.arabidopsis.org/index.jsp). The BnMSTs, BoMSTs, and BrMSTs were identified via two methods. First, BLASTp analysis [44] was performed against the B. napus genome database (BRAD, http://brassicadb.org/brad/index.php) [45] using the AtMST protein sequences as 
queries. The HMMsearch program (HMMER 3.0, http://hmmer.org/) was then used to further confirm the presence of protein domains using the AtMST Pfam numbers as queries.

\subsection{Multiple Sequence Alignment and Phylogenetic Analysis}

Multiple sequence alignment and phylogenetic analysis were performed to investigate the evolutionary relationships of the MSTs among the four species. Multiple sequence alignment was performed with MEGA 7.0 (Molecular Evolutionary Genetics Analysis) with default parameters. A phylogenetic tree was constructed using the neighbor-joining (NJ) method, with bootstrap analysis of 1000 replicates [46]. The tree was further visualized with FigureTree software.

\subsection{Analysis of the Chromosomal Locations, Gene Structures, and Conserved Motifs of the BnMST Genes}

Detailed information about the locations of the BnMST genes, their deduced protein sequences, and the relationships between Brassica and A. thaliana genes was obtained from the Brassica napus Genome Database. The chromosomal distribution of the genes was visualized with Map-Chart2.2 [47]. The gene structures were mapped using the Gene Structure Display Server (GSDS) [48]. The conserved motifs were analyzed using MEME online (http://meme-suite.org/tools/meme) [49,50]; all parameters were set to default settings, except the maximum number of predicted motifs, which was set to 20 .

In addition, we calculated the molecular weights (Mw) and isoelectric points (PI) of the BnMSTs using the ExPASy proteomics server database (https://www.expasy.org/tools/) [51]. The subcellular localizations of the proteins were predicted with MultiLoc2 (https://abi-services.informatik.unituebingen.de/multiloc2/webloc.cgi) [52].

\subsection{RNA-seq Analysis}

Sugar transporters may influence the HI through increased seed yields. To identify the DEGs from the set of 175 BnMST genes identified in high HI materials, we download and analyzed RNA-seq data for B. napus from the NCBI database (ID Number SRP072900). We extracted the transcriptome data for the 175 BnMST genes and constructed a heatmap using R-Studio. The data were generated from seven tissues (stems, mature leaves, buds on the main branch, seeds from the main branch, seeds from lateral branches, silique pericarps from the main branch, and silique pericarps from lateral branches) from four materials with a high or low HI and biological yield (BY) [32].

\subsection{Plant Materials}

To identify the expression patterns of the differentially expressed BnMST genes, which expressed differently for materials with a high and low HI, seeds from the materials CQ24 (SWU47, High HI) and CQ46 (Ning You 12, Low HI) were obtained from the Chongqing Rapeseed Technology Research Center, China. The plants were cultivated under field conditions in Chongqing for 2 years (2016 and 2017). Ten plants of rapeseed were planted in two experimental plots, and each plot contained five individual plants. After the mature stage, the two main characters, consisting of the dry weight of the above-ground biomass yield and seed yield per plant, were investigated. The harvest index was then calculated with the ratio of seed yield to above-ground biomass. Finally, we obtained the HI data of 10 individual plants from two replications respectively. The phenotypes of CQ24 and CQ46 are shown in Table 1. Samples of different tissues during various growth periods (stems at 0 and 30 days after flowering; leaves at the beginning of flowering; and flowers, buds, seeds, and silique pericarps at 7, 14, 21,30 , and $40 \mathrm{~d}$ after flowering) were collected from the two materials, immediately frozen in liquid nitrogen, and stored at $-80^{\circ} \mathrm{C}$ until use.

\subsection{RNA Extraction and Validation of RNA-seq Data by $q R T-P C R$}

RNA was extracted from the samples using an RNeasy Extraction Kit (Invitrogen, Carlsbad, CA, USA) and employed as a template to produce cDNA with a Reverse Transcription Kit 
(TaKaRa Biotechnology, Dalian, China). As described by Qu [53], quantitative reverse-transcription PCR (qRT-PCR) was performed to identify the expression patterns of the DEGs identified by RNA-seq using specific primers designed with Premier 5.0 [54]. The primers, which were confirmed using BLAST online tools (BRAD, http://brassicadb.org/brad/blastPage.php), are shown in Table S1. The UBC21 gene was used as an endogenous reference gene [55]. The relative expression level of each gene was calculated using the $2^{-\Delta \Delta C t}$ method [56]. The qRT-PCR was completed with three technical repetitions. The results were visualized with GraphPad Prism5.0 software [57,58].

Table 1. Harvest index of plant materials during the two years of field tests.

\begin{tabular}{ccccccc}
\hline Trait & Material & $\mathbf{2 0 1 6}$ & $\mathbf{2 0 1 7}$ & Mean Value & SEM & $\boldsymbol{P}$-Value \\
\hline \multirow{2}{*}{ Harvest Index /\% (HI) } & CQ24 & 24.75 & 24.33 & 24.28 & 0.47 & 0.004 \\
& CQ46 & 15.21 & 14.43 & 14.82 & 0.39 & \\
Seed Yield per Plant/g (SY) & CQ24 & 29.60 & 28.13 & 28.86 & 0.73 & 0.004 \\
& CQ46 & 15.21 & 14.37 & 14.79 & 0.42 & \\
\multirow{2}{*}{ Biological Yield per Plant /g (BY) } & CQ24 & 119.60 & 118.15 & 118.87 & 0.73 & 0.002 \\
& CQ46 & 98.60 & 99.55 & 99.08 & 0.48 & \\
\hline
\end{tabular}

\section{Results}

\subsection{Identification and Phylogenetic Analysis of MSTs}

In Arabidopsis, 53 AtMSTs have been identified [8]. In this study, using the amino acid sequences of the 53 AtMSTs as queries, we identified 175 BnMST, 87 BoMST, and 83 BrMST genes by both BLASTP and HMM analyses (Table S2). Notably, only 50 AtMST genes matched the BnMST genes, whereas the three remaining AtMST genes (At3G05160, At1G08890 (AtERD6-like subfamily), and At1G05030 (AtpGlcT subfamily)) lacked homologs in B. napus (Table 2). Detailed information about the BnMST genes is provided in Table S3. The molecular weights (Mw) of the BnMST proteins ranged from 20.06 (BnERD6-like5-1) to 161.72 (BnpGlcT3), and their isoelectric points (PI) ranged from 4.93 (BnTMT3-3) to 10.46 (BnERD6-like3-5) (Table S3).

To explore the evolutionary relationships of the MSTs, we performed a phylogenetic analysis. The 295 MST genes were divided into seven subfamilies in this phylogenetic tree. This result is consistent with previous findings in Arabidopsis [8]. We named the seven subfamilies based on the types of monosaccharides they transport [8]: the sugar transport protein (STP), vacuolar glucose transporter (VGT), tonoplast monosaccharide transporter (TMT), plastidic glucose transporter (pGlcT), polyol transporter (PLT), inositol transporter (INT) and ERD6-like subfamilies (Figure 1).

Table 2. The number of homologous genes among the A and C sub-genomes of Brassica napus, Brassica rapa, Brassica oleracea, and their homologs in Arabidopsis.

\begin{tabular}{cccccc}
\hline Gene Name & A.thaliana & B. rapa & B. oleracea & B.napus $(A)$ & B. napus (C) \\
\hline \multicolumn{7}{c}{ Zero-Copy in B. napus } \\
\hline ERD6-like15 & 1 & 0 & 0 & 0 & 0 \\
ERD6-like16 & 1 & 0 & 0 & 0 & 0 \\
\hline GlcT4 & 1 & 0 & 0 & 0 & 0 \\
\hline PLT2 & 1 & 0 & 1 & 1 & 0 \\
PGlcT3 & 1 & 1 & 1 & 1 & 0 \\
\hline
\end{tabular}


Table 2. Cont.

\begin{tabular}{|c|c|c|c|c|c|}
\hline Gene Name & A. thaliana & B. rapa & B. oleracea & B. napus (A) & B. napus (C) \\
\hline \multicolumn{6}{|c|}{ Two-Copy in B. napus } \\
\hline ERD6-like2 & 1 & 1 & 1 & 1 & 1 \\
\hline ERD6-like4 & 1 & 0 & 1 & 1 & 1 \\
\hline ERD6-like7 & 1 & 1 & 1 & 1 & 1 \\
\hline ERD6-like9 & 1 & 1 & 1 & 1 & 1 \\
\hline ERD6-like10 & 1 & 1 & 1 & 1 & 1 \\
\hline ERD6-like13 & 1 & 1 & 1 & 1 & 1 \\
\hline ERD6-like14 & 1 & 1 & 1 & 1 & 1 \\
\hline$p G l c T 2$ & 1 & 1 & 1 & 1 & 1 \\
\hline STP3 & 1 & 1 & 1 & 1 & 1 \\
\hline STP5 & 1 & 1 & 1 & 1 & 1 \\
\hline STP8 & 1 & 1 & 1 & 1 & 1 \\
\hline STP11 & 1 & 0 & 1 & 1 & 1 \\
\hline STP12 & 1 & 1 & 1 & 1 & 1 \\
\hline STP14 & 1 & 1 & 1 & 1 & 1 \\
\hline VGT2 & 1 & 1 & 1 & 1 & 1 \\
\hline VGT3 & 1 & 1 & 1 & 1 & 1 \\
\hline INT2 & 1 & 1 & 1 & 1 & 1 \\
\hline INT3 & 1 & 1 & 0 & 1 & 1 \\
\hline PLT3 & 1 & 1 & 1 & 1 & 1 \\
\hline PLT4 & 1 & 0 & 0 & 1 & 1 \\
\hline \multicolumn{6}{|c|}{ Three-Copy in B. napus } \\
\hline SFP1 & 1 & 2 & 0 & 3 & 0 \\
\hline TMT2 & 1 & 1 & 1 & 1 & 2 \\
\hline PLT1 & 1 & 3 & 2 & 2 & 1 \\
\hline PLT5 & 1 & 2 & 2 & 1 & 2 \\
\hline \multicolumn{6}{|c|}{ Four-Copy in B. napus } \\
\hline ERD6-like8 & 1 & 1 & 2 & 2 & 2 \\
\hline ERD6-like11 & 1 & 2 & 0 & 2 & 2 \\
\hline SFP2 & 1 & 2 & 3 & 1 & 3 \\
\hline INT1 & 1 & 2 & 2 & 2 & 2 \\
\hline INT4 & 1 & 2 & 2 & 2 & 2 \\
\hline$p G l c T 1$ & 1 & 2 & 2 & 2 & 2 \\
\hline TMT1 & 1 & 2 & 2 & 2 & 2 \\
\hline TMT3 & 1 & 2 & 2 & 2 & 2 \\
\hline STP1 & 1 & 2 & 2 & 2 & 2 \\
\hline STP2 & 1 & 2 & 2 & 2 & 2 \\
\hline STP7 & 1 & 2 & 2 & 2 & 2 \\
\hline STP9 & 1 & 2 & 2 & 2 & 2 \\
\hline STP13 & 1 & 2 & 2 & 2 & 2 \\
\hline \multicolumn{6}{|c|}{ Five-Copy in B. napus } \\
\hline ERD6-like3 & 1 & 2 & 1 & 3 & 2 \\
\hline ERD6-like5 & 1 & 2 & 2 & 3 & 3 \\
\hline ERD6-like12 & 1 & 2 & 2 & 2 & 3 \\
\hline \multicolumn{6}{|c|}{ Six-Copy in B. napus } \\
\hline ERD6-like6 & 1 & 3 & 3 & 3 & 3 \\
\hline STP6 & 1 & 4 & 3 & 4 & 3 \\
\hline STP10 & 1 & 3 & 4 & 3 & 3 \\
\hline PLT6 & 1 & 3 & 3 & 3 & 3 \\
\hline
\end{tabular}


Table 2. Cont.

\begin{tabular}{cccccc}
\hline Gene Name & A.thaliana & B. rapa & B. oleracea & B. napus (A) & B. napus (C) \\
\hline \multicolumn{7}{c}{ Seven-Copy in B. napus } \\
\hline ERD6 & 1 & 3 & 4 & 4 & 3 \\
STP4 & 1 & 3 & 5 & 2 & 3 \\
\hline ERD6-like1 & 1 & Eight-Copy in B. napus \\
VGT1 & 1 & 3 & 3 & 4 & 4 \\
TOTAL & 53 & 3 & 4 & 2 & 6 \\
\hline
\end{tabular}

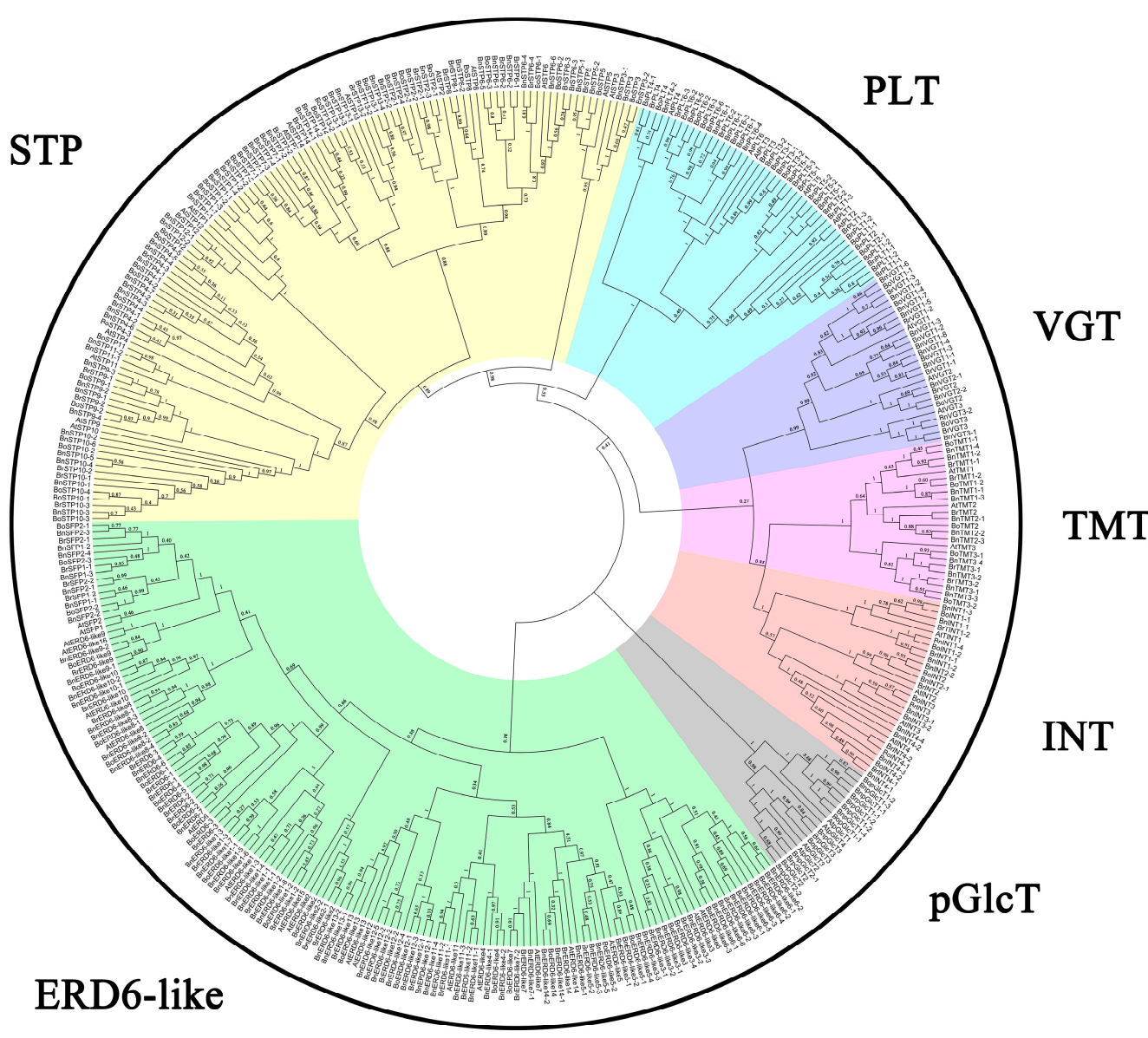

Figure 1. Neighbor-joining (NJ) tree of the monosaccharide transporter (MST) protein sequences from Brassica napus, Brassica rapa, Brassica oleracea, and Arabidopsis thaliana. All MST genes from the four species were divided into seven subfamilies and named PLT1 to STP14. In the names of the BnMST, BoMST, and BrMST genes, the first number indicates the congruent relationship with Arabidopsis and the second number represents the corresponding number in the respective species.

\subsection{Chromosome Locations of BnMST Genes and Duplication Analysis}

The 175 BnMST genes are unevenly distributed on the B. napus chromosomes (Figure 2A), including 86 genes in the A subgenome and 89 in the $C$ subgenome. Of these, 153 BnMST genes were identified on the $19 \mathrm{~B}$. napus chromosomes, and the 22 remaining BnMST genes were mapped to pseudo-molecule chromosomes Ann and Cnn or to Unn (unknown). Chromosomes A01, A03, A05, $\mathrm{A} 06, \mathrm{C} 01$, and C05 each contain more than $10 \mathrm{BnMST}$ genes, whereas chromosomes A02, A04, A10, $\mathrm{C} 02, \mathrm{C} 04, \mathrm{C} 06$, and C09 contain fewer than six BnMST genes (Figure 2A). The syntenic relationships of the 175 BnMST genes are indicated by lines in Figure 2B. Sixty-nine homologous pairs were identified 
among the 175 BnMST genes (Figure 2B). The syntenic relationships among the four species are shown in Figure 2C. The copy numbers of the MST genes in A. thaliana and B. napus ranged from one to eight (Table 2), indicating that some genes were lost or duplicated during evolution. For example, the syntenic homologs of AtERD6-like15, AtERD6-like16, and AtpGlcT4 have been lost in Brassica species. However, three homologous syntenic genes of AtERD6-like6 are present in B. rapa and B. oleracea and six are present in B. napus (three each in the A and C subgenomes) (Figure 2C, Table 2).
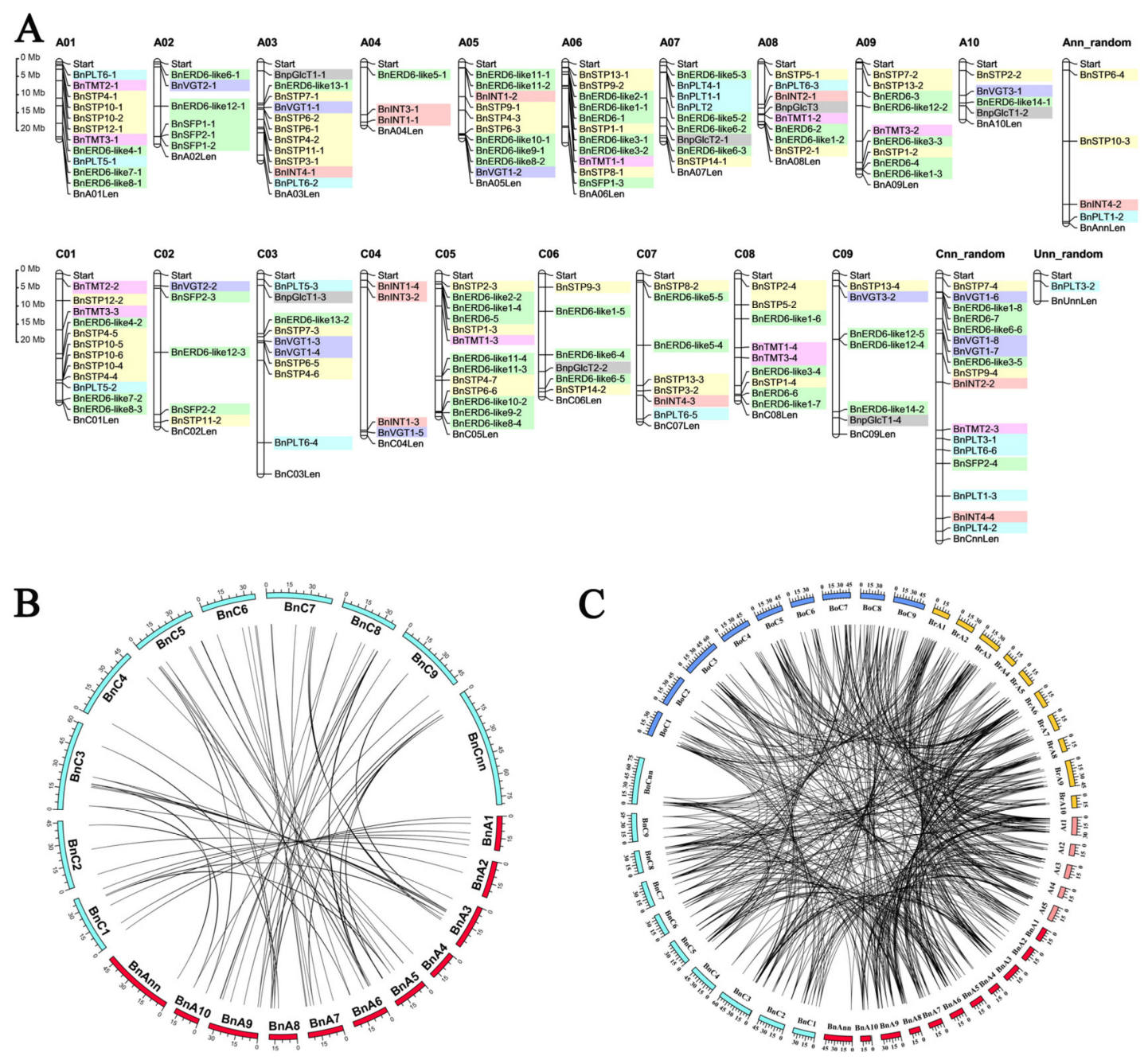

Figure 2. Chromosomal location of the BnMST genes in the B. napus genome and syntenic analysis of MST genes among A. thaliana, B. napus, B. rapa, and B. oleracea. (A) Chromosomal locations of the 175 BnMST genes. The length of each chromosome is marked by the words "Start" and "Len". The seven background colors represent seven different subfamily members of BnMST respectively, as is the case for the colors shown in Figure 1. (B) Syntenic relationships of the 175 BnMST genes, as indicated by connecting lines. (C) Syntenic relationships of MST genes among the four species, as indicated by connecting lines. (A) and (C) are the two main chromosomes in B. napus; 01 to 10 represent chromosome numbers and $\mathrm{Mb}$ indicates megabases. Ann and $\mathrm{Cnn}$ represent pseudo-molecule chromosomes and Unn indicates that the specific position is unknown. The five different colors in Figure $2 \mathrm{C}$ means chromosomes from diverse species or the same species' chromosome from diverse sub-genomes.

\subsection{Exon-Intron Structures and Conserved Motif Analysis of the BnMSTs}

We analyzed the exon-intron structures and conserved motifs of the BnMSTs to obtain additional information about their protein profiles (Figure 3). The number of exons ranged from 2 (BnSTP4-2) to 33 (BnVGT1-1). Genes in the BnERD6-like subfamily (except BnERD6-like1, BnERD6-like3, 
and BnERD6-like6) and BnSTP subfamily (BnSTP2, BnSTP4, BnSTP6, BnSTP8, BnSTP9, BnSTP10, and BnSTP11) contained significantly fewer exons than genes in the other subfamilies. This analysis, combined with phylogenetic analysis of the BnMSTs, indicated that the higher the homology of the sequences, the more similar their genetic structures. For example, BnSTP9-1 and BnSTP9-4 have highly similar gene structures, as do BnSTP10-2 and BnSTP10-6, whereas the exon-intron structures of BnSTP9-1, BnSTP9-4 vs. BnSTP10-2, BnSTP10-6 are significantly different.

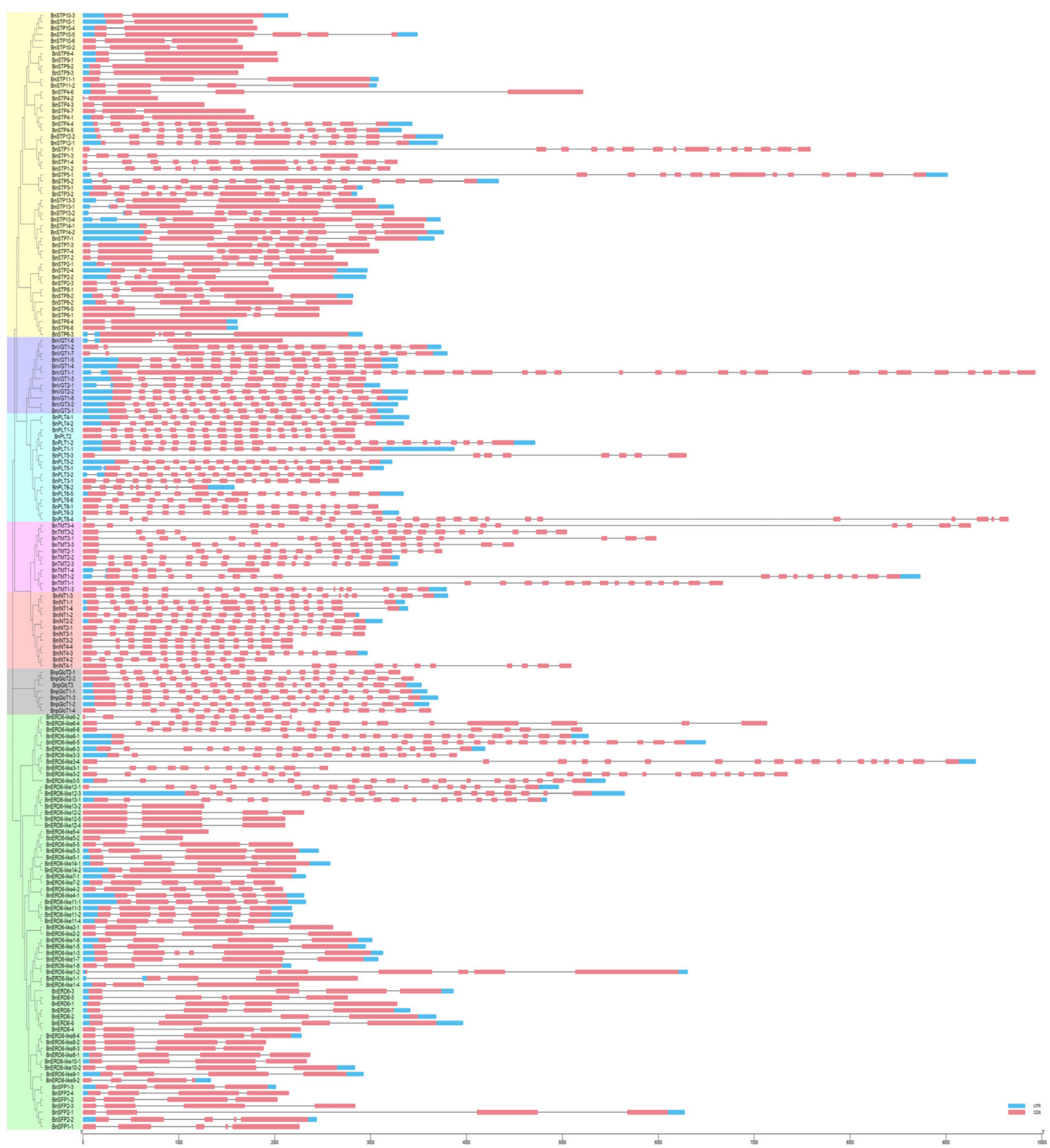

Figure 3. Exon-intron structures of the $175 \mathrm{BnMST}$ genes based on their phylogenetic relationships. The phylogenetic tree was constructed using the protein sequences of 175 BnMSTs with 1000 bootstrap replicates.

Twenty conserved motifs were predicted using the MEME server (Figure 4 and Figure S1). Motif 10 is present in all BnMST family members except STP, and motif 13 is in all BnMST family members except INT and PLT. Motifs 9 and 20 are only present in the BnSTP subfamily and motif 19 is only present in the BnSTP, BnINT, and BnERD6-like subfamilies. The BnSTP and BnpGlcT subfamilies contain unique motif 15 and 17 , respectively. 
We predicted the subcellular localizations of the proteins using the online tool MultiLoc2 (Table S3). Most of the BnMST proteins were predicted to be located in the cytoplasm (45 BnMST proteins), chloroplast (34 BnMST proteins), or nucleus (12 BnMST proteins), and the others were predicted to be in secretory pathways.

\subsection{RNA-seq Analysis of the 175 BnMST Genes}

To identify DEGs of the BnMST genes among materials with a high and low HI, we analyzed publicly available RNA-seq data (Table S4). We then constructed a heatmap of the expression patterns of the 175 BnMST genes (Figure 5). The genes showed various expression patterns, depending on the subfamily classification. Overall, BnpGlcT subfamily genes were expressed at significantly higher levels than genes in the six other subfamilies, especially the BnERD6-like subfamily. However, many genes had different expression patterns, even within the same subfamily. For example, BnPLT1, BnPLT2, BnPLT6, BnVGT1, BnTMT3, BnINT3, BnINT4, BnERD6-like1, BnERD6-like4, BnERD6-like7, BnERD6-like8, BnERD6-like12, BnERD6-like13, BnSTP10, and BnSTP11 were expressed at low levels in almost every organ (marked with yellow in Figure 5), but their homologous genes were expressed at high levels in specific tissues (indicated by blue arrows, green and red ellipses in the heatmap, Figure 5). Among these, many genes were differentially expressed between silique pericarps and seeds, including BnPLT3, BnPLT4, BnPLT5, BnVGT1, BnVGT2, BnVGT3, BnTMT1, BnTMT2, BnINT1, BnINT2, BnpGlcT1, BnpGlcT2, BnERD6-like3, BnERD6-like5, BnERD6-like6, BnERD6-like9, BnERD6-like10, BnERD6-like14, BnSFP1, BnSFP2, BnSTP1, BnSTP3, BnSTP4, BnSTP5, BnSTP6, BnSTP7, BnSTP12, and BnSTP13. We identified 31 genes that were specifically expressed in silique pericarps and seeds and were differentially expressed in materials with extremely high vs. low HI values (indicated by red ellipses in Figure 5).

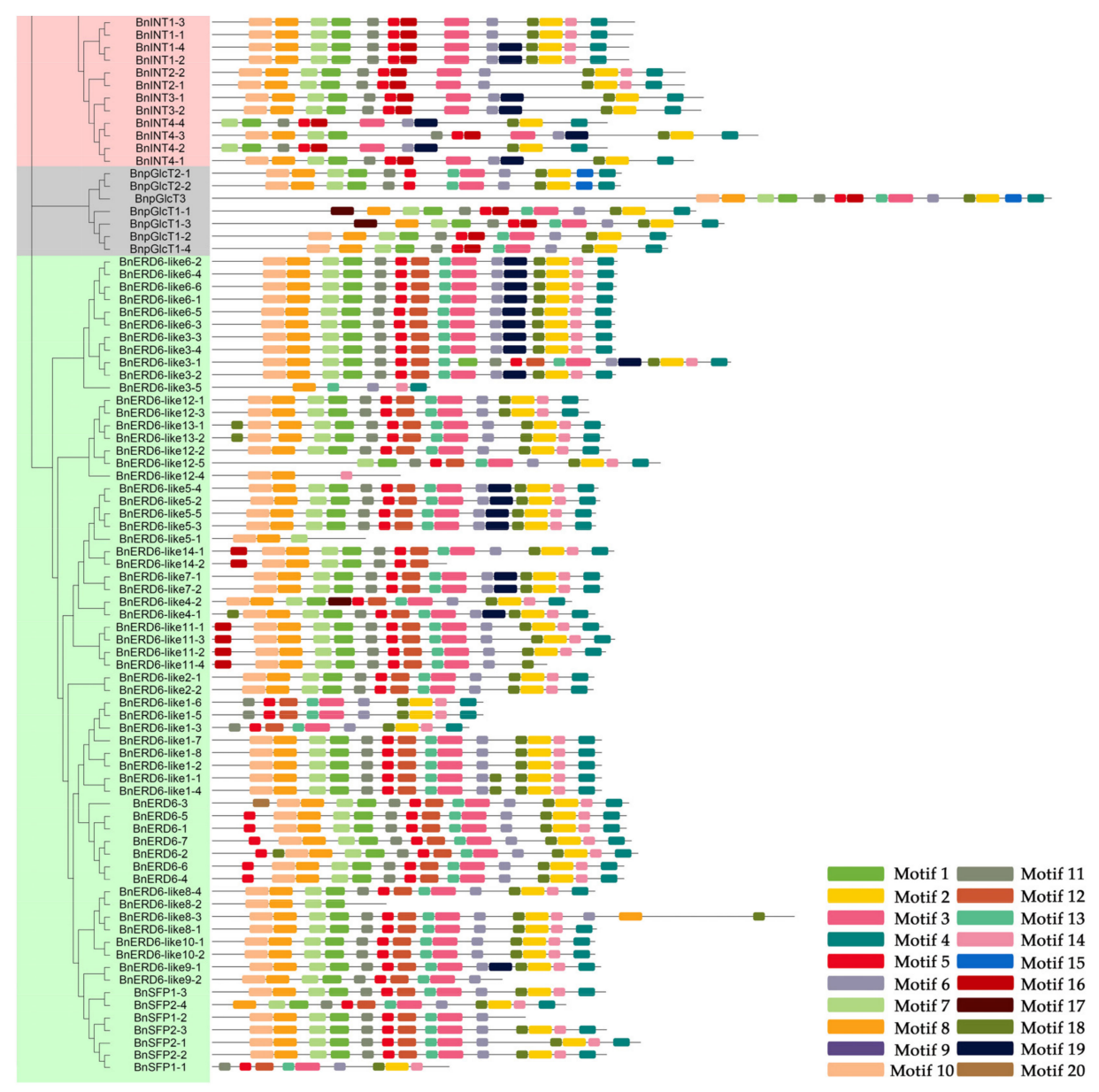

Figure 4. Cont. 


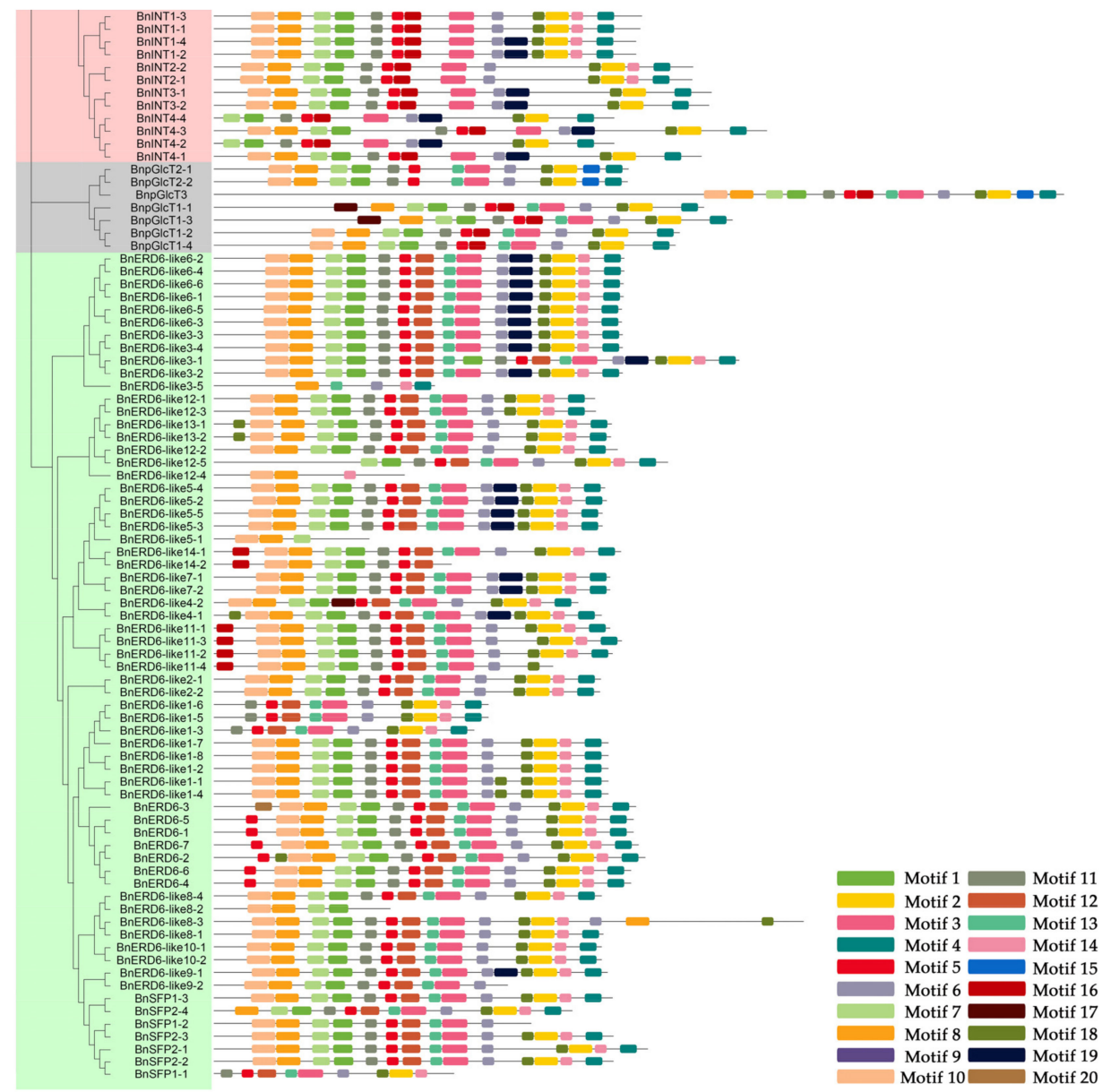

Figure 4. Conserved motifs of the 175 BnMSTs based on their phylogenetic relationships; gray lines indicate non-conserved sequences. Weblogo plots of the 20 conserved motifs are presented in Figure S1.

\section{5. qRT-PCR Analysis of DEGs in Different Tissues between Diverse Materials}

We performed qRT-PCR to examine the expression patterns of the 31 DEGs in diverse tissues of plants at different stages of growth between materials with extremely high (CQ24) and low (CQ46) HI values (Figure 6, Table 1). The phenotype of plants and siliques between CQ24 and CQ46 are shown in Figure 6A,B, respectively. Phenotype analysis indicated that the traits of the harvest index (HI), seed yields (SY), and biological yields (BY) were significantly different between the two materials (Figure 6C).

These 31 genes were specifically expressed in different tissues, growth stages, and materials (Figure 7 and Figure S2, Table S5). We divided the DEGs into two major categories based on the qRT-PCR results: BnSTP1, BnSTP7, BnSTP13, BnTMT1, BnTMT2, BnINT2, BnpGlcT2, BnPLT5, BnERD6, and BnERD6-like5 were highly expressed in silique pericarps (Figure 7B), whereas BnSTP5, BnSTP12, BnERD6-like10, and BnERD6-like14 were highly expressed in seeds (Figure 7A). In addition, BnVGT2-2 was only expressed in line CQ24 (Figure S2). The expression levels of several DEGs increased rapidly in seeds and silique pericarps during the later period of plant growth and development (30-40 d after flowering), including BnSTP5, BnSTP12, BnINT2, BnpGlcT1, BnpGlcT2, BnPLT3, BnPLT5, BnERD6-like5, and BnERD6-like10. Perhaps the genes that are expressed at higher levels in silique pericarps (source organs) play roles in photosynthate loading into source organs, whereas genes expressed specifically in seeds (sink organs) might play important roles in the unloading of carbohydrates. These results suggest that these BnMST genes might increase the HI of B. napus by enhancing the translocation of assimilates to grains (seeds) and that the BnMST genes likely play essential roles in the transport of monosaccharides during the later stages of seed growth and development. 


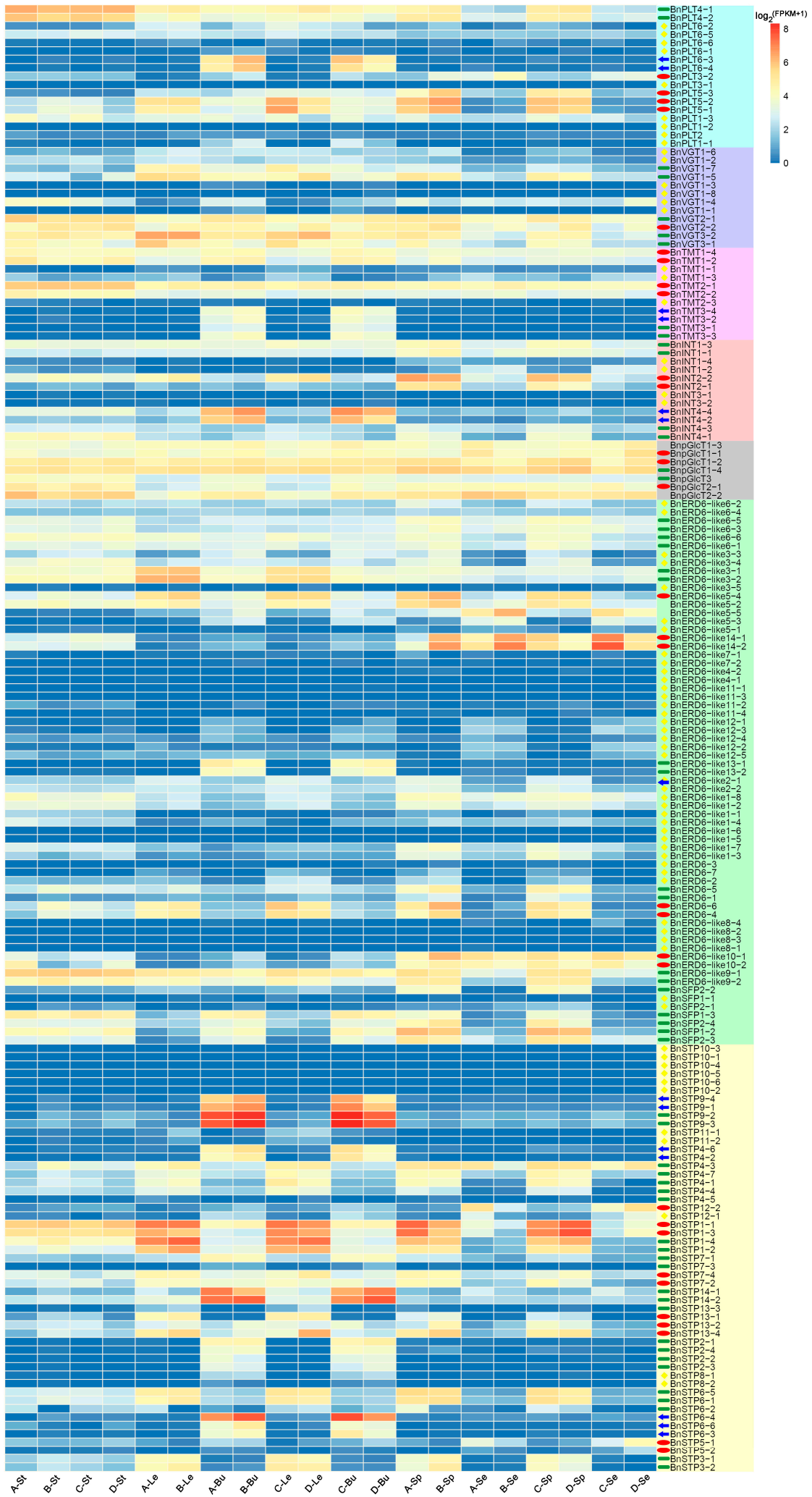

Figure 5. Heatmap of the expression patterns of the 175 BnMST genes in various tissues between different materials. A, B, C, and D represent different materials: A: High biological yield (BY) but low harvest index (HI); B: high BY and HI; C: low BY but high HI; D: low BY and low HI; J, Le, ZL, ZJ, CJ, ZS, and CS represent the different tissues: J: stems; Le: mature leaves; ZL: buds on the main branch; ZJ: silique pericarps from the main branch; CJ: silique pericarps from the lateral branch; ZS: seeds from the main branch; CS: seeds from the lateral branch. Different colors represent different expression levels. 


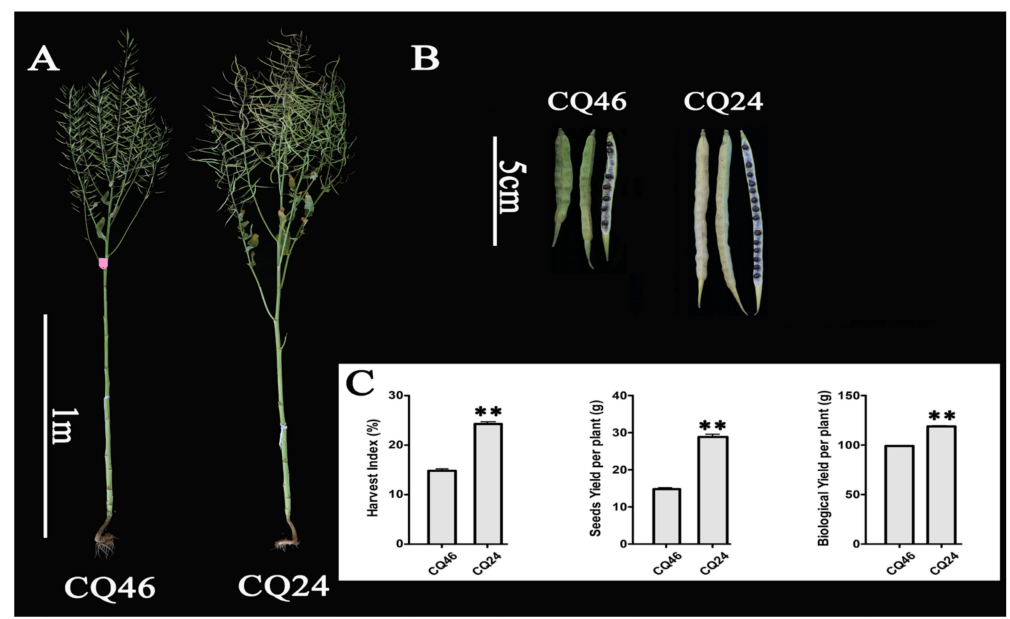

Figure 6. Phenotypic analysis of the materials CQ24 and CQ46 in Brassica napus. Phenotype of the plants and siliques is shown in (A) and (B), respectively. The traits of the harvest index (HI), seed yields (SY), and biological yields (BY) between the two materials are shown in (C). The value of the experiment was 2. CQ24 (SWU47) has a high HI, SY, and BY, whereas CQ46 (Ning You 12) has a low HI, SY, and BY. **: significant difference at $p<0.01$.
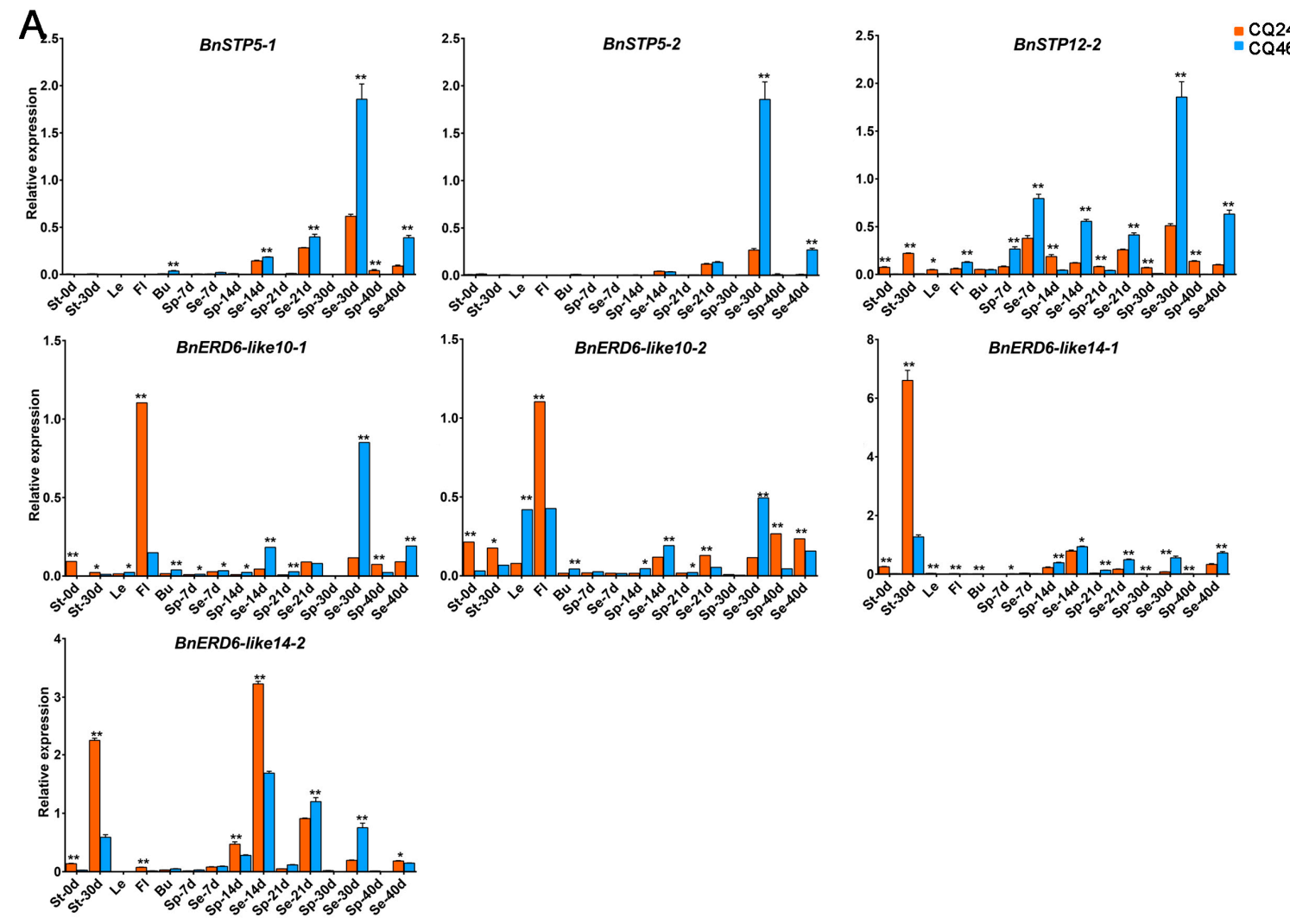

Figure 7. Cont. 
B
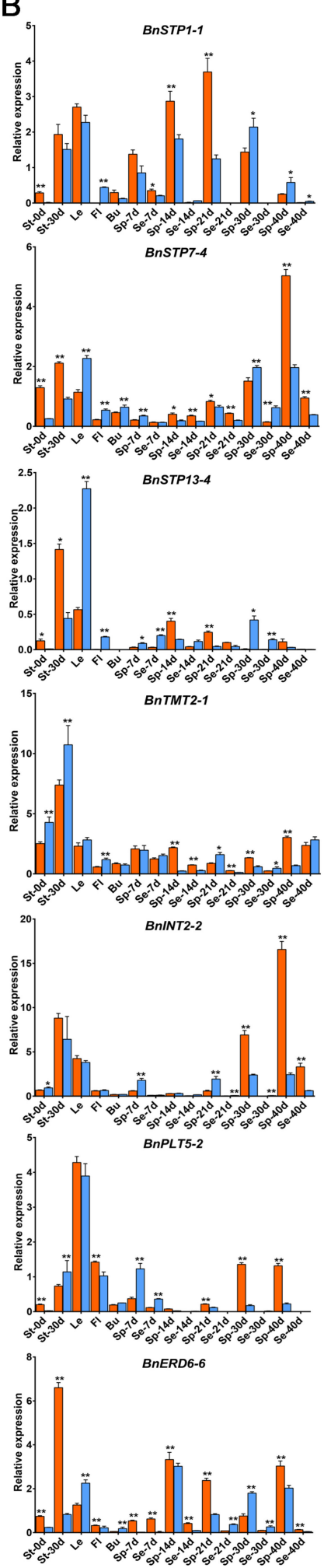
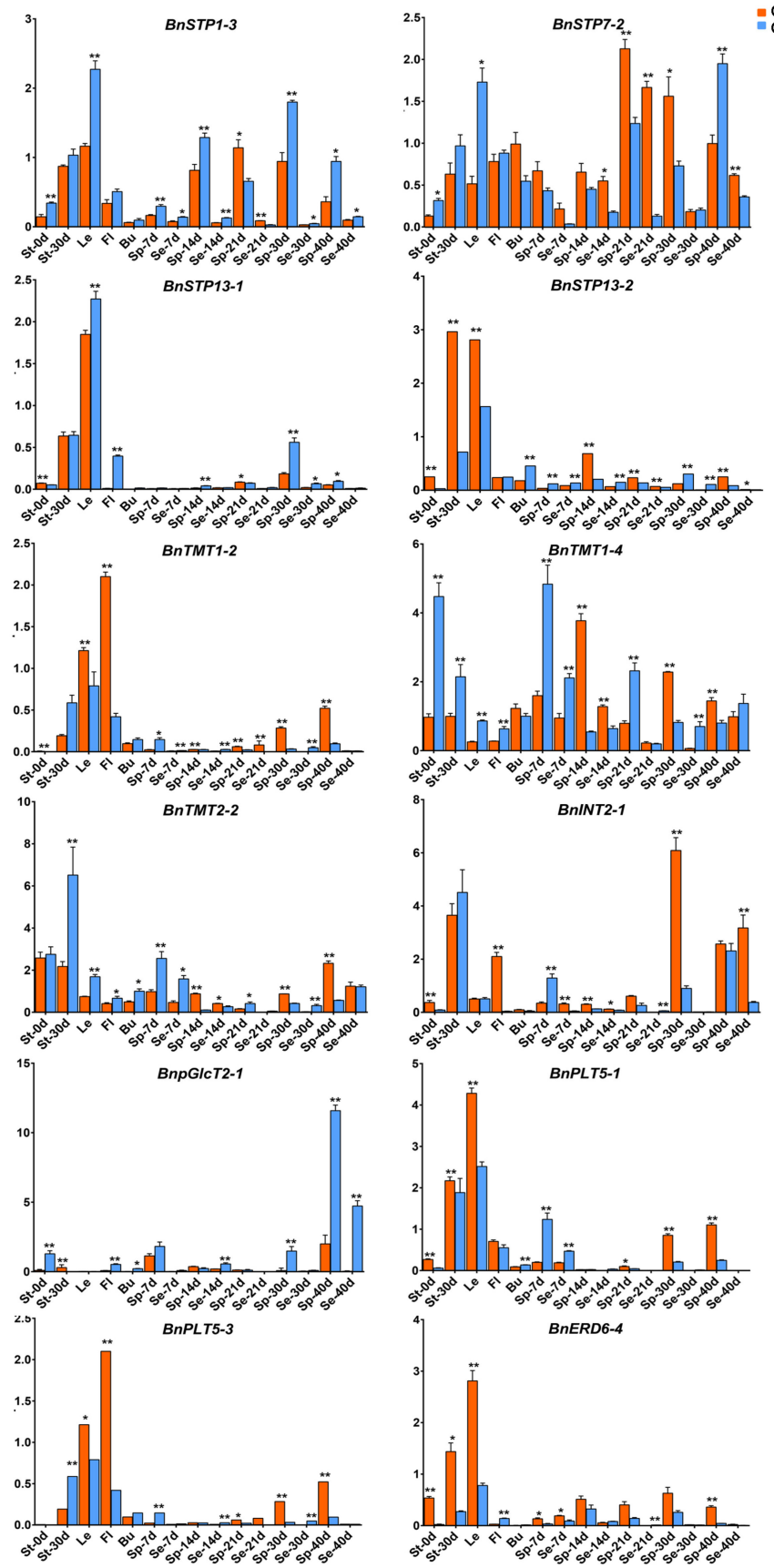

Figure 7. Expression patterns of the differentially expressed genes (DEGs) in different tissues and growth periods between two plant materials with an extremely high (CQ24) and low (CQ46) HI. (A) Expression patterns of 7 identified DEGs, which expressed extremely higher in source organs (seeds). (B) Expression patterns among 19 identified DEGs, which expressed extremely higher in sink organs (silique pericarp). The letter " $\mathrm{d}$ " indicates days after flowering; St: stem; Le: leaves at the beginning of flowering; Fl: flower; Bu: bud; Sp: silique pericarp; Se: seed; *: significant difference at $p<0.05 ;{ }^{* *}$ : significant difference at $p<0.01$. 


\section{Discussion}

B. napus (AACC, $2 \mathrm{n}=38$ ) is an allotetraploid plant derived from two diploid species (B. rapa, $\mathrm{n}=10$, and $B$. oleracea, $\mathrm{n}=9$ ) [59], as confirmed by numerous experimental crosses. The genetic relationships of these species are described by the " $\mathrm{U}^{\prime} \mathrm{s}$ triangle" model. Comparative genomic analysis between $A$. thaliana and B. rapa has clearly confirmed the occurrence of a whole genome triplication (WGT) event [60] millions of years ago [61,62]. In the current study, we identified 175 MST genes from B. napus. However, we identified one to eight homologs of each AtMST gene in B. napus, rather than six for every gene (Figure 2C, Table 2), perhaps due to genome shrinkage and redundancy. Indeed, Mun et al. reported that genome shrinkage and the differential loss of duplicated genes occurred after the WGT event [63], and other studies have provided insights into the processes of genome duplication, loss, or retention [64,65]. In addition, we identified 87 and 83 MST genes from B. oleracea and B. rapa, respectively. The number of BnMST genes in B. napus (175) is greater than the sum of BoMST and BrMST genes (Table 2), pointing to possible redundancy among the BnMST genes. When we constructed a phylogenetic tree for the four plant species, all MST genes were assigned to seven subfamilies (Figure 1) based on the nomenclature used in A. thaliana [8]. Interestingly, the seven subfamilies did not all follow the same patterns of gene redundancy. The INT subfamily was fully compliant with the WGT event, whereas the number of B. napus genes in the PLT, STP, and pGlcT subgroups was less than the sum of genes in B. rapa and B. oleracea, suggesting that gene elimination occurred in these three subgroup (Figure 2C, Table 2).

By combining the results of the gene structure, conserved motif, and protein analysis of the BnMSTs, we determined that genes from the same subgroup have similar features. For example, BnSTP and BnERD6-like subfamily members have significantly fewer exons than genes in the five other subfamilies (Figure 3). Similarly, only BnSTP subfamily members contain motif 9 and 20, and most BnMST family members (except BnSTP subfamily proteins) contain motif 10. Furthermore, motif 19 is only present in the BnSTP, BnERD6-like, and BnINT subfamilies (Figure 4). Interestingly, BnSTP (especially BnSTP10) and BnERD6-like subfamily members were expressed at much lower levels than members of the five other subgroups, as shown in the heatmap (Figure 5, genes marked with yellow triangles). In conclusion, gene redundancy and gene elimination occurred during the genomic evolution of BnMST, which further drove the diversification of homologous genes in B. napus. In addition, during the genomic evolution of the BnMST genes, changes in exon-intron structures might have resulted in different coding regions, thereby altering the expression patterns and functions of these genes [66].

Among BnMST family members, we were interested in identifying genes with vital functions in seed development and ripening. We therefore analyzed RNA-seq data for the phenotypic characters related to the HI (Table S4) and used the gene expression patterns to construct a heatmap (Figure 5). Most, but not all, BnMST genes in the same subfamilies had similar expression patterns. For example, genes from the BnpGlcT subfamily were ubiquitously expressed in all tissues, whereas genes in the six other subfamilies were expressed in specific tissues (Figure 5). However, BnSTP5 and BnSTP13, which belong to the same subfamily, showed completely different expression profiles: BnSTP5 expression strongly increased during the later stage of seed development, whereas BnSTP13 was primarily expressed in leaf tissue at the beginning of flowering and in stems at $30 \mathrm{~d}$ after flowering (DAF; Figure 7B). These results suggest that homology does not necessarily reflect a similar function. There were some discrepancies between the heatmap and qRT-PCR results, perhaps due to the different materials and diverse RNA samples examined.

Whereas the expression of BnSTP5 strongly increased in seeds at 30 DAF, BnSTP1 was mainly expressed in silique pericarps at 14-30 DAF (Figure 7A), suggesting that STP1 might contribute to sugar uptake and is primarily expressed in the early stage of seed development [38]. BnSTP13 was only strongly expressed in stems at $30 \mathrm{DAF}$ and in leaves at the beginning of flowering. This expression pattern is in complete agreement with reports on Arabidopsis, which suggest that overexpressing AtSTP13 could improve the glucose uptake capacity and increase the plant biomass or enhance 
disease resistance [36,37,67]. STP8 is highly expressed in reproductive organs, whereas STP7 plays an important role in sugar uptake and recycling in the cell wall [68]. STP6 and STP13 are the only genes known to function in fructose transport among STP subfamily members [67].

AtPLT5 encodes another plasma membrane transporter responsible for fructose uptake; this gene is primarily expressed in sink tissues [69]. In contrast, in the current study, BnPLT5 was primarily expressed in leaves at the beginning of flowering and in silique pericarps at 30-40 DAF (Figure 7B), perhaps because the silique pericarp can act as a source or sink tissue at different stages of plant development. The TMT subfamily members TMT1 and TMT2 are highly expressed in various tissues and might be important for the seed yield, whereas TMT3 is barely expressed throughout a plant's lifecycle $[27,70]$. The expression patterns of pGlct, INT, and VGT subfamily members were different from those identified in previous studies, perhaps due to the different species analyzed.

Interestingly, several genes were more strongly expressed in materials with low, as opposed to high, HI values, such as BnSTP5, BnSTP12, BnERD6-like10, and BnERD6-like14 (Figure 7A). Among BnMST family members, only these genes were expressed at significantly higher levels in seeds than in silique pericarps. Luo et al. suggested that the HI is primarily influenced by the relationship between "source", "flow", and "sink" and that "flow" is the crucial limiting factor when the "source" is sufficient and the "sink" is not fully utilized [34]. Based on this finding, we hypothesize that BnSTP5, BnSTP12, and BnERD6-like14 take part in the sugar unloading process in sink organs and that a negative feedback effect might occur among these BnMST genes when the "sink" is full. Perhaps the roles of these BnMST genes could be functionally verified in the future.

To better explore the localizations and interactions of the BnMST proteins, we predicted their subcellular localizations using an online tool. The 175 BnMST proteins are localized to diverse compartments, such as the cytoplasm, chloroplast, mitochondria, and nucleus (Table S3). In A. thaliana, pGlcT and MEX1 function in the export of starch degradation products from chloroplasts [71]. However, we predicted that BnpGlcT1 is localized to chloroplasts, whereas BnpGlcT2 is localized to the cytoplasm (Table S3), suggesting that functional segregation might occur in the same subfamily. Furthermore, BnSTP5, BnSTP12, and BnERD6-like14, which are encoded by genes with similar expression patterns, are all located in secretory pathways, indicating that some BnMST proteins likely interact with other proteins from different subfamilies.

\section{Conclusions}

In the current study, we performed a systematic study of the BnMST gene family. Genome-wide identification, phylogenetic analysis, and syntenic analysis among B. napus, B. oleracea, B. rapa, and $A$. thaliana indicated that gene redundancy and elimination occurred during the evolution of BnMST family members. Our analysis of RNA-seq data, gene structures, and conserved motifs indicated that changes in the exon-intron structure could lead to the presence of different coding regions and alter gene expression patterns and functions. Based on subcellular localization and expression analysis of DEGs between materials with two different HI values, BnSTP5, BnSTP13, BnPLT5, and BnERD6-like14, which are specifically expressed in seeds, silique pericarps, or stems, represent excellent candidate genes for further functional studies. Our findings provide basic information about MST genes in Brassica napus and uncover several candidate genes related to the HI for further analysis.

Supplementary Materials: The following are available online at http://www.mdpi.com/2073-4425/11/6/653/s1: Figure S1: Weblogo plots of the 20 conserved motifs; Figure S2: Expression pattern of the other five DEGs in different tissues and growth periods between two plant materials with extremely high (CQ24) and low (CQ46) HI values; Table S1: Specific primers used for qRT-PCR analysis of the 31 DEGs; Table S2: Homologous genes among the A and C sub-genomes of B. napus, B. rapa, B. oleracea, and their homologs in Arabidopsis; Table S3: Complete list of the 175 BnMST genes identified in our study; Table S4: RNA-seq data for the 175 BnMST genes; Table S5: Expression analysis and significance tests among the 31 DEGs.

Author Contributions: J.L. (Jiana Li) and K.L. designed the experimental program; L.Z., C.Z., B.Y., J.M., H.J., and C.Q. performed the bioinformatics analysis; C.Z., Z.X., and J.L. (Jingsen Liu) performed the RNA extraction 
and qRT-PCR experiments; L.Z. wrote the paper. All authors have read and agreed to the published version of the manuscript.

Funding: This research was funded by The National Key Research and Development Plan (2018YFD0100500), the National Natural Science Foundation of China (31830067, U1302266), the 111 Project (B12006), and the Department of Agriculture Projects of Modern Agricultural Technology System (CARS-13).

Conflicts of Interest: The authors declare no conflicts of interest.

\section{References}

1. Weise, S.E.; Schrader, S.M.; Kleinbeck, K.R.; Sharkey, T.D. Carbon balance and circadian regulation of hydrolytic and phosphorolytic breakdown of transitory starch. Plant Physiol. 2006, 141, 879-886. [CrossRef] [PubMed]

2. Peng, D.; Gu, X.; Xue, L.J.; Leebens-Mack, J.H.; Tsai, C.J. Bayesian phylogeny of sucrose transporters: ancient origins, differential expansion and convergent evolution in monocots and dicots. Front. Plant. Sci 2014, 5, 615. [CrossRef] [PubMed]

3. Bel, A.J.E.V. The phloem, a miracle of ingenuity. Plant. Cell Environ. 2003, 26, 125-149.

4. Kuhn, C.; Franceschi, V.R.; Schulz, A.; Lemoine, R.; Frommer, W.B. Macromolecular trafficking indicated by localization and turnover of sucrose transporters in enucleate sieve elements. Science 1997, 275, 1298-1300. [CrossRef]

5. Zheng, Q.M.; Tang, Z.; Xu, Q.; Deng, X.X. Isolation, phylogenetic relationship and expression profiling of sugar transporter genes in sweet orange (Citrus sinensis). Plant. Cell Tiss. Org. 2014, 119, 609-624. [CrossRef]

6. Zhang, L.Y.; Peng, C.C.; Zou, K.Q.; Wang, X.L.; Fan, R.C.; Yu, X.C.; Zhang, X.Y.; Shen, Y.Y.; Zhang, D.P. A monosaccharide transporter is localized to sieve plate and plasmodesmal channel in developing apple fruit. Chinese Sci Bull. 2005, 50, 429-434. [CrossRef]

7. Johnson, D.A.; Hill, J.P.; Thomas, M.A. The monosaccharide transporter gene family in land plants is ancient and shows differential subfamily expression and expansion across lineages. BMC Evol. Biol. 2006, 6, 64 .

8. Büttner, M. The monosaccharide transporter (-like) gene family in Arabidopsis. Febs Lett. 2007, 581, $2318-2324$. [CrossRef]

9. Smith, A.M.; Zeeman, S.C.; Smith, S.M. Starch degradation. Annu. Rev. Plant. Biol. 2005, 56, 73-98. [CrossRef]

10. Patrick, J.W. PHLOEM UNLOADING: Sieve Element Unloading and Post-Sieve Element Transport. Front. Plant. Sci. 1997, 48, 191-222. [CrossRef]

11. Patrick, J.W. Does Don Fisher's high-pressure manifold model account for phloem transport and resource partitioning? Front. Plant. Sci. 2013, 4, 184. [CrossRef] [PubMed]

12. Guo-Liang, W.; Xiao-Yan, Z.; Ling-Yun, Z.; Qiu-Hong, P.; Yuan-Yue, S.; Da-Peng, Z.J.P.; Physiology, C. Phloem unloading in developing walnut fruit is symplasmic in the seed pericarp and apoplasmic in the fleshy pericarp. Plant. Cell Physiol. 2004, 45, 1461-1470.

13. Lalonde, S.; Tegeder, M.; Throne-Holst , M.; Frommer, W.B.; Patrick, J.W. Phloem loading and unloading of sugars and amino acids. Plant. Cell Env. 2010, 26, 37-56. [CrossRef]

14. Haupt, S.; Duncan, G.H.; Holzberg, S.; Oparka, K. Evidence for symplastic phloem unloading in sink leaves of barley. Plant. Physiol. 2001, 125, 209-218. [CrossRef]

15. Giaquinta, R.T.; Lin, W.; Sadler, N.L.; Franceschi, V.R. Pathway of Phloem unloading of sucrose in corn roots. Plant. Physiol. 1983, 72, 362-367. [CrossRef]

16. Hackel, A.; Schauer, N.; Carrari, F.; Fernie, A.R.; Grimm, B.; Kuhn, C. Sucrose transporter LeSUT1 and LeSUT2 inhibition affects tomato fruit development in different ways. Plant. J. 2006, 45, 180-192. [CrossRef]

17. Rae, A.L.; Grof, C.P.L.; Casu, R.E.; Bonnett, G.D. Sucrose accumulation in the sugarcane stem: pathways and control points for transport and compartmentation. Field Crops Res. 2005, 92, 159-168. [CrossRef]

18. Sherson, S.M.; Alford, H.L.; Forbes, S.M.; Wallace, G.; Smith, S.M. Roles of cell-wall invertases and monosaccharide transporters in the growth and development of Arabidopsis. J. Exp. Bot. 2003, 54, 525-531. [CrossRef]

19. Weschke, W.; Panitz, R.; Gubatz, S.; Wang, Q.; Radchuk, R.; Weber, H.; Wobus, U. The role of invertases and hexose transporters in controlling sugar ratios in maternal and filial tissues of barley caryopses during early development. Plant. J. 2003, 33, 395-411. [CrossRef] 
20. Sauer, N.; Tanner, W. The hexose carrier from Chlorella. cDNA cloning of a eucaryotic H+-cotransporter. FEBS Lett. 1989, 1, 43-46. [CrossRef]

21. Sauer, N.; Friedländer, K.; Gräml-Wicke, U. Primary structure, genomic organization and heterologous expression of a glucose transporter from Arabidopsis thaliana. EMBO J. 1990, 10, 3045-3050. [CrossRef]

22. Sauer, N.; Stadler, R. A sink-specific H+/monosaccharide co-transporter from Nicotiana tabacum: cloning and heterologous expression in baker's yeast. Plant. J. Cell Mol. Biol. 1993, 4, 601-610. [CrossRef] [PubMed]

23. Deborah, A.J.; Michael, A.H. The monosaccharide transporter gene family in Arabidopsis and rice: a history of duplications, adaptive evolution, and functional divergence. Mol. Biol. Evol. 2007, 11, 2412-2423.

24. Hayes, M.A.; Davies, C.; Dry, I.B. Isolation, functional characterization, and expression analysis of grapevine (Vitis vinifera L.) hexose transporters: differential roles in sink and source tissues. J. Exp. Bot. 2007, 58, 1985-1997. [CrossRef]

25. Marger, M.D.; Saier, M.H. A major superfamily of transmembrane facilitators that catalyse uniport, symport and antiport. Trends Biochem. Sci. 1993, 18, 13-20. [CrossRef]

26. Hediger, M.A. Structure, function and evolution of solute transporters in prokaryotes and eukaryotes. J. Exp. Biol. 1994, 196, 15-49. [PubMed]

27. Wingenter, K.; Schulz, A.; Wormit, A.; Wic, S.; Trentmann, O.; Hoermiller, I.I.; Heyer, A.G.; Marten, I.; Hedrich, R.; Neuhaus, H.E. Increased Activity of the Vacuolar Monosaccharide Transporter TMT1 Alters Cellular Sugar Partitioning, Sugar Signaling, and Seed Yield in Arabidopsis. Plant. Physiol. 2010, 154, 665-677. [CrossRef] [PubMed]

28. Zhu, Z. Molecular cloning and expression analysis of a monosaccharide transporter gene OsMST4 from rice (Oryza sativa L.). Plant. Mol. Biol. 2007, 65, 439-451.

29. Yamaguchi, J. Characterization of Rice Functional Monosaccharide Transporter, OsMST5. Biosci. Biotechnol. Biochem. 2014, 67, 556-562.

30. Jian, H.; Lu, K.; Bo, Y.; Wang, T.; Li, Z.; Zhang, A.; Jia, W.; Liu, L.; Qu, C.; Li, J. Genome-Wide Analysis and Expression Profiling of the SUC and SWEET Gene Families of Sucrose Transporters in Oilseed Rape (Brassica napus L.). Front. Plant. Sci. 2016, 7, 1464. [CrossRef]

31. Hay, R.K.M. Harvest index: A review of its use in plant breeding and crop physiology. Ann. Appl. Biol. 2008, 126, 197-216. [CrossRef]

32. Lu, K.; Xiao, Z.; Jian, H.; Peng, L.; Qu, C.; Fu, M.; He, B.; Tie, L.; Liang, Y.; Xu, X. A combination of genome-wide association and transcriptome analysis reveals candidate genes controlling harvest index-related traits in Brassica napus. Sci. Rep. 2016, 6, 36452. [CrossRef] [PubMed]

33. Luo, X.; Ma, C.; Yue, Y.; Hu, K.; Li, Y.; Duan, Z.; Wu, M.; Tu, J.; Shen, J.; Yi, B. Unravelling the complex trait of harvest index in rapeseed (Brassica napus L.) with association mapping. BMC Genom. 2015, 16, 379. [CrossRef] [PubMed]

34. Shen, J.X.; Fu, T.D.; Yang, G.S.; Ma, C.Z.; Tu, J. Genetic analysis of rapeseed self-incompatibility lines reveals significant heterosis of different patterns for yield and oil content traits. Plant. Breed. 2010, 124, 111-116. [CrossRef]

35. Chhabra, M.L. Translocation pattern of assimilates in Indian mustard. Int. Rapeseed Congr. 1988, $25,102$.

36. Lemonnier, P.; Gaillard, C.; Veillet, F.; Verbeke, J.; Lemoine, R.; CoutosThévenot, P.; La Camera, S. Expression of Arabidopsis sugar transport protein STP13 differentially affects glucose transport activity and basal resistance to Botrytis cinerea. Plant. Mol. Biol. 2011, 85, 473-484. [CrossRef]

37. Schofield, R.A.; Bi, Y.M.; Kant, S.; Rothstein, S.J. Over-expression of STP13, a hexose transporter, improves plant growth and nitrogen use in Arabidopsis thaliana seedlings. Plant. Cell Environ. 2008, 32, 271-285. [CrossRef]

38. Sherson, S.M.; Hemmann, G.; Wallace, G.; Forbes, S.; Smith, S.M. Monosaccharide/proton symporter AtSTP1 plays a major role in uptake and response of Arabidopsis seeds and seedlings to sugars. Plant. J. 2000, 24, 849-857. [CrossRef]

39. Afoufa-Bastien, D.; Medici, A.; Jeauffre, J.; CoutosThévenot, P.; Lemoine, R.; Atanassova, R.; Laloi, M. The Vitis vinifera sugar transporter gene family: phylogenetic overview and macroarray expression profiling. BMC Plant. Biol. 2010, 10, 245. [CrossRef]

40. Deng, X.; An, B.; Zhong, H.; Yang, J.; Li, Y. A Novel Insight into Functional Divergence of the MST Gene Family in Rice Based on Comprehensive Expression Patterns. Genes 2019, 10, 239. [CrossRef] [PubMed] 
41. Qin, L.; Dang, H.; Chen, Z.; Wu, J.; Chen, Y.; Chen, S.; Luo, L. Genome-Wide Identification, Expression, and Functional Analysis of the Sugar Transporter Gene Family in Cassava (Manihot esculenta). Int. J. Mol. Sci. 2018, 19, 987.

42. Jia-ming, L.; Dan-man, Z.; Lei-ting, L.; Qiao, X.; Shu-wei, W.; Bai, B.; Shao-ling, Z.; Wu, J. Genome-Wide Function, Evolutionary Characterization and Expression Analysis of Sugar Transporter Family Genes in Pear (Pyrus bretschneideri Rehd). Plant. Cell Physiol. 2015, 9, 1721-1737.

43. Szenthe, A.; Schfer, H.; Hauf, J.; Schwend, T.; Wink, M. Characterisation and expression of monosaccharide transporters in lupins, Lupinus polyphyllus and L. albus. J. Plant. Res. 2007, 120, 697-705. [CrossRef] [PubMed]

44. ALTSCHUL, S.F. Gapped BLAST and PSI-BLAST: a new generation of protein detabase search programs. Nucleic Acids Res. 1997, 25, 3389-3402. [CrossRef] [PubMed]

45. Cheng, F.; Liu, S.; Wu, J.; Fang, L.; Sun, S.; Liu, B.; Li, P.; Hua, W.; Wang, X. BRAD, the genetics and genomics database for Brassica plants. BMC Plant. Biol. 2011, 11, 136. [CrossRef]

46. Sudhir, K.; Glen, S.; Koichiro, T. MEGA7: Molecular Evolutionary Genetics Analysis Version 7.0 for Bigger Datasets. Mol. Biol. Evol. 2016, 7, 1870-1874.

47. Voorrips, E.R. MapChart: Software for the Graphical Presentation of Linkage Maps and QTLs. J. Hered. 2002, 93, 77-78. [CrossRef]

48. Guo, A.Y.; Zhu, Q.H.; Chen, X.; Luo, J.C. GSDS: A gene structure display server. Hereditas 2007, $29,1023-1026$. [CrossRef]

49. Bailey, T.L.; Nadya, W.; Chris, M.; Li, W.W. MEME: discovering and analyzing DNA and protein sequence motifs. Nucleic Acids Res. 2006, 34, 369-373. [CrossRef]

50. Bailey, T.L.; Mikael, B.; Buske, F.A.; Martin, F.; Grant, C.E.; Luca, C.; Ren, J.; Li, W.W.; Noble, W.S. MEME Suite: tools for motif discovery and searching. Nucleic Acids Res. 2009, 37, 202-208. [CrossRef]

51. Elisabeth, G.; Alexandre, G.; Christine, H.; Ivan, I.; Appel, R.D.; Amos, B. ExPASy: the proteomics server for in-depth protein knowledge and analysis. Nucleic Acids Res. 2003, 13, 3784-3788.

52. Hoglund, A.; Donnes, P.; Blum, T.; Adolph, H.-W.; Kohlbacher, O. MultiLoc: prediction of protein subcellular localization using N-terminal targeting sequences, sequence motifs and amino acid composition. Bioinformatics 2006, 22, 1158-1165. [CrossRef] [PubMed]

53. Qu, C.; Fuyou, F.; Miao, L.; Huiyan, Z.; Chuan, L.; Jiana, L.; Zhanglin, T.; Xinfu, X.; Xiao, Q.; Rui, W. Comparative Transcriptome Analysis of Recessive Male Sterility (RGMS) in Sterile and Fertile Brassica napus Lines. PLoS ONE 2015, 10, e0144118. [CrossRef] [PubMed]

54. Singh, V.K.; Mangalam, A.K.; Dwivedi, S.; Naik, S. Primer Premier: Program for Design of Degenerate Primers from a Protein Sequence. Biotechniques 1998, 24, 318-319. [CrossRef] [PubMed]

55. Wu, G.; Zhang, L.; Wu, Y.; Cao, Y.; Lu, C. Comparison of Five Endogenous Reference Genes for Specific PCR Detection and Quantification of Brassica napus. J. Agric. Food Chem. 2010, 58, 2812-2817. [CrossRef]

56. Livak, K.; Schmittgen, T. Analysis of Relative Gene Expression Data Using Real-Time Quantitative PCR and the 2- $\triangle \triangle$ Ct Method. Methods 2000, 25, 402-408. [CrossRef]

57. Steland, A. Book Review: Fitting Models to Biological Data Using Linear and Nonlinear Regression. By Harvey Motulsky und Arthur Christopoulos. Biom. J. 2006, 48, 327. [CrossRef]

58. Swift, M.L. GraphPad Prism, Data Analysis, and Scientific Graphing. J. Chem. Inf. Modeling 1997, 37, 411-412.

59. Cheng, F.; Wu, J.; Wang, X. Genome Triplication Drove the Diversification of Brassica Plants. Hortic. Res. 2014, 1, 14024. [CrossRef]

60. Lysak, M.A.; Cheung, K.; Kitschke, M.; Bures, P. Ancestral Chromosomal Blocks Are Triplicated in Brassiceae Species with Varying Chromosome Number and Genome Size. Plant. Physiol. 2007, 145, 402-410. [CrossRef]

61. Wang, X.W.; Wang, H.Z.; Wang, J.; Sun, R.F.; Wu, J.; Liu, S.Y. The genome of the mesopolyploid crop species Brassica rapa. Nat. Genet. 2011, 43, 1035-1039. [CrossRef] [PubMed]

62. Arias, T.; Beilstein, M.A.; Tang, M.; Mckain, M.R.; Pires, J.C. Diversification times among Brassica (Brassicaceae) crops suggest hybrid formation after 20 million years of divergence. Am. J. Bot. 2014, 1, 86-91. [CrossRef] [PubMed]

63. Mun, J.H.; Kwon, S.J.; Yang, T.J.; Seol, Y.J.; Jin, M. Genome-wide comparative analysis of theBrassica rapagene space reveals genome shrinkage and differential loss of duplicated genes after whole genome triplication. Genome Biol. 2009, 10, R11. [CrossRef] [PubMed] 
64. Moghe, G.D.; Hufnagel, D.E.; Tang, H.; Xiao, Y.; Dworkin, I.; Town, C.D.; Conner, J.K.; Shiu, S.H. Consequences of Whole-Genome Triplication as Revealed by Comparative Genomic Analyses of the Wild Radish Raphanus raphanistrum and Three Other Brassicaceae Species. Plant. Cell 2014, 26, 1925-1937. [CrossRef]

65. Ma, J.Q.; Jian, H.J.; Yang, B.; Lu, K.; Zhang, A.X.; Liu, P.; Li, J.N. Genome-wide analysis and expression profiling of the GRF gene family in oilseed rape (Brassica napus L.). Gene 2017, 620, 36-45. [CrossRef] [PubMed]

66. Xu, G.; Guo, C.; Shan, H.; Kong, H. Divergence of duplicate genes in exon-intron structure. Proc. Natl. Acad. Sci. USA 2012, 109, 1187-1192. [CrossRef]

67. NRholm, M.H.H.; NourEldin, H.H.; Brodersen, P.; Mundy, J.; Halkier, B.A. Expression of the Arabidopsis high-affinity hexose transporter STP13 correlates with programmed cell death. FEBS Lett. 2006, 580, 2381-2387. [CrossRef]

68. Rottmann, T.M.; Klebl, F.; Schneider, S.; Kischka, D.; Rüscher, D.; Sauer, N.; Stadler, R. Characterization of three sugar transporters, STP7, STP8 and STP12. Plant. Physiol. 2018, 3. [CrossRef]

69. Reinders, A.; Panshyshyn, J.A.; Ward, J.M. Analysis of Transport Activity of Arabidopsis Sugar Alcohol Permease Homolog AtPLT5. J. Biol. Chem. 2005, 280, 1594-1602. [CrossRef]

70. Wormit, A.; Trentmann, O.; Feifer, I.; Lohr, C.; Tjaden, J.; Meyer, S.; Schmidt, U.; Martinoia, E.; Neuhaus, H.E. Molecular Identification and Physiological Characterization of a Novel Monosaccharide Transporter from Involved in Vacuolar Sugar Transport. Plant. Cell 2006, 18, 3476-3490. [CrossRef]

71. Cho, M.H.; Lim, H.; Shin, D.H.; Jeon, J.S.; Bhoo, S.H.; Park, Y.I.; Hahn, T. Role of the plastidic glucose translocator in the export of starch degradation products from the chloroplasts in Arabidopsis thaliana. New Phytol. 2011, 190, 101-112. [CrossRef] [PubMed]

(C) 2020 by the authors. Licensee MDPI, Basel, Switzerland. This article is an open access article distributed under the terms and conditions of the Creative Commons Attribution (CC BY) license (http://creativecommons.org/licenses/by/4.0/). 